\title{
HACERSE CHINAS. MujerES Y NACIONALISMO EN LA POSREVOLUCIÓN CHIAPANECA
}

\author{
Miguel Lisbona-Guillén
}

\section{Introducción}

E s sabido que los vaivenes políticos de la posrevolución mexicana tuvieron en el nacionalismo un punto de encuentro de políticos e intelectuales, y dentro de esa eclosión simbólica y discursiva en busca de definir la nación mexicana destacaron las acciones xenófobas hacia colectivos de inmigrantes, en las que los chinos se convirtieron en objetivo de ataques de toda naturaleza, incluidas agresiones violentas o expulsiones del país. Es en esta última acción en la que aparecen los matrimonios entre asiáticos y mexicanas y todas las medidas tomadas para evitarlos e, incluso, el abandono del Estado mexicano hacia sus coterráneas quellegaron a China acompañando a sus maridos alejados forzosamente de México, por citar sólo dos de los aspectos relacionados con la unión entre mexicanas y chinos. En este texto se presentan dos documentos procedentes de la hemeroteca histórica resguardada por la Universidad de Ciencias y Artes de Chiapas. El primero, por orden cronológico, es una carta signada por "un chiapaneco" y dirigida al director del periódico Evolución, Santiago Serrano. En ella se condensan todas las preocupaciones y opiniones estereotipadas vertidas contra los inmigrantes chinos entre las que se incluye, por supuesto, el problema de los enlaces de mujeres mexicanas con asiáticos y los hijos resultantes de los mismos. El segundo documento corresponde al editorial del periódico La Vanguardia, que, como el anterior, se editaba en la capital de Chiapas, Tuxtla Gutiérrez. Publicado nueve años después del primero, en 1931, refiere la preocupación de las autoridades chiapanecas por restringir, a través de la legislación, los matrimonios entre mexicanas y chinos. No es una reproducción de las leyes y decretos del periodo posrevolucionario puesto que ello ocuparía demasiado espacio en esta sección de Documentos, pero invita a la búsqueda sistemática de dicha legislación para conocer la percepción y las acciones del ejecutivo de Chiapas respecto a los inmigrantes asiáticos y al papel de las mujeres en tal situación. Así, las páginas que componen este texto tienen la intención de poner

Miguel Lisbona Guillén, Universidad Nacional Autónoma de México.

Recibido: 9 de febrero de 2015. 
en contexto los datos aparecidos en los documentos, al mismo tiempo que incitan, a quienes tengan interés en el pasado, a hurgar en las fuentes primarias en busca de un mayor conocimiento del tema en el estado.

\section{El matrimonio con chinos. Una decisión con consecuencias sociales}

No es éste el espacio para recorrer las formas en que ciertos inmigrantes se incorporan a las sociedades de acogida a través del matrimonio o la creación de una familia; sin embargo, hay que destacar que esa ha sido una de las estrategias para permanecer en el país, aunque no siempre lo deseado era posible. Algunas referencias orales de la península de Yucatán, por ejemplo, señalan las dificultades de adaptación de los chinos en las plantaciones de henequén, así como la negativa de las mujeres a casarse con ellos "porque los chinos puro arroz comen" (Comunidades Eclesiales de Chablekal y Dzibilchaltún, 1991: 8). En Chiapas, la inmigración china se caracterizó por ser de hombres, con muy pocas referencias a alguna mujer procedente del país asiático (Lisbona, 2014: 115). El resultado de ello fue un gran índice de hombres chinos solteros en los primeros censos levantados en los municipios de la costa chiapaneca, en concreto de Tapachula, pero ello no es óbice para pensar que soltero significara que no compartía el hogar con una mujer mexicana. En suelo chiapaneco, como en otros lugares de la República mexicana, los matrimonios o el amasiato, como gustaba señalarse entonces, fueron hechos comunes y se constatan de forma empírica en las generaciones que en el tiempo han dado visibilidad a la huella china, principalmente en la costa chiapaneca. El recuerdo de esta realidad es perceptible en entrevistas actuales que mezclan el dato de lo acontecido con discursos racialistas que impregnan el decir cotidiano u observaciones vinculadas con la división clasista entre los inmigrantes chinos:

Hay varios señores chinos que tienen sus hijos mestizos que tal vez en otro tiempo hubieran pensado traerle una chinita para que se casara con ellos y seguir conservando la pureza de la raza. Antes así lo hacían: iban y hacían sus compromisos allá en China y se traían a la novia, o se casaban allá para facilitar el ingreso. Eso lo hacían los más pudientes, los demás iban agarrando de aquí del país. (Olegario Liy, Tapachula, 11 de mayo de 2007).

Sin embargo, lo que hoy es considerado parte del legado de una migración histórica tuvo episodios de indudable dramatismo personal vivido, sobre todo, por las mujeres mexicanas que compartieron su vida con los inmigrantes asiáticos. No sólo se trataba de la discriminación anunciada de forma reiterada por políticos o por la opinión pública que podía horrorizarse "al pensar que quizá uno de mis nietos llegará a unir sus destinos con un chino, muy ricachón, muy vivaracho; pero muy degenerado y fumador de opio", ${ }^{1}$ sino de una auténtica persecución por compartir su vida con un inmigrante chino. Ello convirtió a estas mujeres en chinas para las autoridades mexicanas, en especial cuando se produjeron las expulsiones del territorio mexicano, como ocurrió en el estado de Sonora. En concreto, en el censo de 1930 de dicho estado la población china era de 3571 hombres y 412 mujeres. Sin embargo, como bien apunta Gómez Izquierdo (1991: 139), dichas mujeres eran principalmente mexicanas que al contraer nupcias con asiáticos perdieron su nacionalidad de origen.

Moisés González es con certeza uno de los primeros científicos sociales mexicanos que hurgó en este hecho denigrante para el país y que afectó la integridad física y las condiciones de vida de muchas compatriotas. A tal efecto, González recuerda que fue Manuel Tello, cónsul mexicano en Yokohama, quien el 6 de abril de 1931 informó reiteradamente al Gobierno nacional de las comunicaciones que le transcribían mexicanas casadas con chinos que habían sido expulsadas junto con sus esposos al país de origen de ellos. Tan dramática era la situación percibida por el funcionario, que incluso propuso que el consulado se trasladara a Cantón, ya que de allí procedía la mayoría de los chinos expulsados. Las mujeres mexicanas en sus escritos y solicitudes hablaban de la falta de dinero o de la inexistencia de 
sus documentos mexicanos, ora porque sus maridos se los retenían, ora porque los habían perdido. En muchos casos, tras el arribo a tierras chinas sus maridos las abandonaron porque ya contaban con una familia en su país o eran consideradas como segundas esposas. "Pero lo peor era que en China no eran ni chinas ni mexicanas", decía González, y afirmó que en 1932 fueron más de cuatrocientas mexicanas las que se encontraban en China, "algunas con niños de entre tres y diez años, casi todos nacidos en México" (González, 1994, III: 94).

En similar sentido, Felipe Pardinas reprodujo documentos consulares que secundaban lo hasta ahora expuesto. El mismo cónsul ya referido con residencia en Japón, Manuel Tello, recibió cartas de mexicanos establecidos en Shanghái, por ejemplo la de Mauricio Fresno, quien dramáticamente afirmaba que:

\section{[...] todavía estoy bajo la impresión de la miseria en que viven estas pobres mujeres [...] La mujer que vi hoy vive en un cuarto de apenas dos metros cuadrados (creo mismo que es mucho) y allí es todo el hogar y según me dijojamás sale pues de miedo por no saber el chino y por la miseria en que vive. Así son las demás mexicanas que están en Nankín y en cuanto a las que viven en Cantón la cosa es todavía peor (Pardinas, 1982: 428).}

Dada esta situación, e incluso los malos tratos que reportaron otras mujeres de sus maridos (Pardinas, 1982: 428-429), el cónsul preguntó a su superior en México qué debía hacer:

1. En caso de mexicanas casadas con chinos ipuedo autorizarles el regreso, aun sin permiso de la Secretaría de Gobernación?

2. ¿Es necesario que presenten el permiso del marido?

3. Si no tienen pasaportes ipuedo expedirles algún documento que las identifique como, por ejemplo, una tarjeta de inmigración?

4. ¿Puedo hacer, oficialmente, gestiones con las compañías navieras para que les hagan algún descuento, etc., como si se tratara de mexicanas que conservasen su nacionalidad?
5. ¿Puedo, oficialmente, hacergestiones antelosmaridos, autoridades, etc., a pesar de que se trata de mujeres casadas con chinos y de que no tengo ninguna jurisdicción sobre China? (Pardinas, 1982: 429).

Estos datos no fueron aislados, puesto que el cónsul honorario de México en Shanghái, Mauricio Fresco, también a finales de 1932, en concreto el 29 de diciembre, informó de la precaria condición en la que se encontraban las mujeres expulsadas de Sonora y Sinaloa. Su intención era "llamar de nuevo la atención de nuestro Gobierno sobre la situación grave de las mexicanas que se encontraban en China, y la carta del Cónsul General de los Estados Unidos en Hong Kong da una idea del estado de algunas personas después que mandó a dicho Cónsul a averiguar el estado de las personas mencionadas" (Pardinas, 1982: 462).

El panorama informado por Mauricio Fresco no difería mucho del apuntado por el cónsul en Yokohama:

1. Varias de estas mujeres casadas con chinos son abandonadas por sus esposos [...].

2. Muchas de ellas son abandonadas porque el esposo se casa con alguna china [...].

3. Muchas de ellas resultan ser "ilegítimas" en vista de la costumbre que existe en China, que los niños son casados cuando tienen diez o veinte años por acuerdo de los parientes [...].

4. Muchas mexicanas les pasa que varios chinos ya estaban casados antes de salir para México, y por la ley china la primera mujer es la legítima [...]

5. Después de la expulsión de los chinos de México, la prensa de China y en lo particular la del sur, [...] ha hecho una propaganda en contra de México y contra estas mexicanas que vienen casadas con chinos [...].

6. Según he averiguado yo mismo al paso de algunas mexicanas por este puerto varias de ellas fueron engañadas por los chinos diciendo haber obtenido permiso para entrar en los Estados Unidos, y nuestras paisanas varias de ellas que guardan la nacionalidad mexicana salieron con "tarjeta de turista" con destino a California, una vez en 
los Estados Unidos del Norte las autoridades americanas expulsan a los chinos y las mujeres mexicanas no tienen más remedio que seguir a los esposos chinos [...].

7. Algunas de nuestras paisanas son tratadas brutalmente por los chinos [...] y apenas si les dan de comer (Pardinas, 1982: 462-463).

Entrado el año 1933, la Secretaría de Relaciones Exteriores de México seguía comentando los distintos oficios transmitidos por Mauricio Fresco respecto a "los sufrimientos de las mujeres mexicanas casadas con ciudadanos chinos, que han acompañado a sus esposos al ser expulsados de nuestro país a la República China". ${ }^{2}$ No se cuenta con datos precisos de la existencia de mujeres chiapanecas en estas condiciones, aunque algún ejemplo en la historia oral refiere esta peculiar travesía vital de principios del siglo XX:

Mi esposo sí nació en China [...]. Su papá [de su esposo] vino acá, se casó con una señora de Sinaloa y se fueron para allá [China], allá el señor se murió y se quedó con su mamá, solos [...]. Cuando la señora se vio sola recurrió a la embajada para que la trajeran porque su marido había muerto y pues ya la trajeron [...]. No sé cuándo regresó a México, ni platicamos de eso, para ellos son recuerdos difíciles, por eso ese tema no muy lo tratamos (Rosalinda Jo, Pijijiapan, 24 de mayo de 2007).

Sería de interés conocer si realmente se dieron estos casos; sin embargo, lo que es claro y constatable gracias a fuentes documentales y a la historia oral es la existencia de hijos que, por distintos motivos, fueron enviados a China y posteriormente tuvieron dificultades para regresar o lo hicieron de forma muy tardía. Por ejemplo Amable Palacios, viuda de Chong, solicitó a la Secretaría de Gobernación que se ordenara o acordara la "repatriación de 6 de sus hijos, que están en Cantón, y así poder pagar los gastos del traslado". ${ }^{3}$

Otros casos informan de cómo el periodo de inestabilidad política de la Revolución mexicana propició que algunos de los chinos asentados en territorio chiapaneco mandaran:

[...] a sus dos hijos y a su esposa mexicana a China, en un barco de vapor [...] Mi padre y mi tío mexicanos, nacidos aquí, y mi abuela nacida en Tuxtla Chico, fueron unas de las primeras gentes en llegar a China. Mi padre y mi abuela estuvieron veintidós años en China. Como hubo una guerra en esa época, el general Lázaro Cárdenas sacó a los mexicanos que estaban allá. Ahí se vinieron nuevamente mi papá, mi tío y la abuela [...] (Enrique Juan Inchon Barrios, Cacahoatán, 13 de febrero de 2007).

Pero esos acontecimientos históricos, de los que nos falta información de fuentes primarias, no tendrían sentido sin su contextualización en la época, como se pretende hacer con brevedad en los siguientes apartados.

\section{La persecución estructurada: las organizaciones antichinas}

Elincremento del discurso nacionalista y la trasposición de un biologismo que se decía científico para el análisis y la comprensión de la composición social de México son elementos cruciales para entender cómo en los años veinte aparecieron agrupaciones antichinas en el país. Inicialmente originados en el norte y dotados de características federales en la ciudad de México, estos grupos, encabezados en muchos casos por beligerantes políticos activos en el denuesto y persecución de los chinos y sus descendientes en suelo mexicano, tuvieron un accionar que no se limitó al norte de la República, sino que procuraron extender sus reclamos a estados donde existía presencia china. Este es el caso de Chiapas, que vio aparecer grupos de esta naturaleza a finales de los años veinte y principios de los treinta del siglo XX (Lisbona, 2014), pero la presión sobre los políticos chiapanecos se ejerció con anterioridad; por ejemplo, en 1925 el presidente del Comité Anti-Chino de Torreón se dirigió al gobernador estatal para "conocer su criterio sobre este particular" porque "consideramos el asunto chino, uno de los principales problemas que 
el actual Gobierno tiene que resolver". Cobijados por el "C. Presidente de la República, Gral. P. Elías Calles, y los Sres. Alejo Bay y Carlos Garza Castro, Gobernadores de los estados de Sonora y Coahuila, respectivamente", afirma que tales funcionarios elogiaron su labor "dentro del orden y la Ley", porque su propósito era "contrarrestar esta pacífica invasión".

La contestación del gobernador chiapaneco se hizo en el tono del discurso nacional, al afirmar que los chinos "no producen y que sí absorben", además de hacer énfasis en su condición de "transmisores de enfermedades, de lacras y de vicios que causan la degeneración de la raza”. Ante tal situación, y queriéndose ceñir a la legislación vigente, concluía que, aunque no se prohibiera la inmigración, "debería ser estricta y cuidadosamente vigilada o inspeccionada por los empleados de migración en las fronteras y en los puertos, no permitiéndose la entrada más que a los que aportaran al país capital suficiente" y quienes no tuvieran enfermedades que incidieran en la "degeneración de la raza". ${ }^{5}$ A agrupaciones como la mencionada se unieron otras que, sin señalar en su nombre el carácter de antichinas, tenían entre sus propósitos esta condición e incluso pretendían incorporar a mujeres en esa lucha contra los migrantes chinos y los matrimonios mixtos, como lo demostró la creación de subcomités femeninos que dependían de las ligas nacionalistas (Gómez Izquierdo, 1991: 121).

Otro ejemplo lo aporta la Unión Nacionalista Mexicana (Pro-Raza y Salud Pública) formada, según su acta constitutiva, para el "mejoramiento intelectual, moral y físico especialmente de la Nación Mexicana, pugnando por llegar a la abolición de los casamientos de mexicanos de ambos sexos con individuos de razas degeneradas y muy especialmente chinos (asiáticos) que degeneran a los pueblos". ${ }^{6}$ Un destacado político y escritor antichino, José Ángel Espinoza, también dirigió al Gobierno federal las consideraciones fundamentales y la declaración de principios del Comité Pro-Raza de la Ciudad de México. En tal escrito se afirmaba que era una "necesidad humana y un deber de todos los mexicanos, evitar la degeneración racial; por lo tanto, con base de [sic] teorías genéticas universales y con la experiencia, evitará, por todos los medios correctos posibles, la mestización de mujeres de raza mexicana con individuos de raza china". ${ }^{7}$ Estas afirmaciones ya habían sido expuestas en sus obras, en las que señalaba, de manera totalmente explícita, el papel de la "pobre mujer" relacionada con los chinos, usada en los trabajos más abyectos por la "necesidad de ganarse la vida” (Espinoza, 1931: 91). Igualmente, utilizó términos especiales en la campaña desatada contra los asiáticos y su inserción en la sociedad mexicana: chineros y chineras. Los primeros eran los:

[...] padres de familia sin corazón, que, por el interés de usufructuar los desperdicios de una tienda de abarrotes, hacen que sus hijas casen o se amanceben con chinos. En esta categoría se cuentan, también, esas mujeres detestables que son más propiamente pálidas floraciones de las inmundas cloacas sociales, que se entregan al comercio carnal y clandestino con individuos de nacionalidad mongólica (Espinoza, 1931: 154).

Despojados de su condición humana, esos "hombres perros" y "mujeres cloacas" son considerados una vergüenza, incluso de "los sapos y las lombrices" (Espinoza, 1931: 154-155). Por tal motivo, la chinera que decidía casarse con un chino se representaba, por ejemplo, como: "desastrada y cochina, cuyos hijos, semejantes a escuálidos ratones, no tendrán un solo rasgo característico de ella, ya que es bien sabido que de la unión de un chino con una mexicana, nacen chinitos tan legítimos que no niegan al padre ni en la piel amarilla, ni en los ojillos buscadores y tracomatosos, pero ni en las mañas, inclinaciones y vicios" (Espinoza, 1931: 169). Estas manifestaciones contrarias a los matrimonios entre mexicanas y chinos también tuvieron resonancia en las acciones gubernamentales.

\section{El gobierno entra en escena}

Las medidas para impedir la inmigración china, así como el matrimonio entre asiáticos y mexicanas, tuvieron dos claras vertientes legislativas: por una parte, las reformas 
a la legislación migratoria y a los códigos sanitarios y, por otra, las transformaciones en los códigos civiles. Si se inicia con estos últimos, hay que señalar que en Chiapas existía la Ley de Relaciones Familiares de 1917 que, en teoría, debía asegurar los derechos familiares de las mujeres y la igualdad entre ambos sexos, aspecto que se vería reflejado en el Código Civil de 1928, en el que, según Jiménez (2010: 8), aparecen algunas de las exigencias de los movimientos feministas a nivel nacional. En este último código, además, las mujeres podían laborar fuera de su hogar sin contar con el permiso de sus maridos. También trataba la figura del concubinato y se instituía la posibilidad legal de investigar la paternidad (Jiménez, 2010: 108). A nivel nacional, Andrés Magallón propuso en 1929 una iniciativa para reformar la Ley de Inmigración y el Código Sanitario de la República. Tomando diversas citas periodísticas que inciden en el peligro representado por los chinos y su presencia en el país, deseaba legitimar su propuesta encaminada a evitar "la degeneración y el monopolio" del chino, "tipo étnico, extraño y complicado". Ante tal situación creía "un deber de alto nacionalismo y de salvación y mejoramiento de raza, emprender, desde ahora, una campaña enérgica en contra de la inmigración que motiva estas líneas".

En este mismo sentido, unos años más tarde el gobernador de Chiapas le turnó al presidente de la República, Emilio Portes Gil, un texto que pretendía dirigir al congreso estatal y que estaba pensado para restringir la inmigración china en territorio chiapaneco. El argumento del escrito hacía referencia, como parece que no podía ser de otra forma por los tiempos que corrían, a la "degeneración en nuestra raza, motivada por los enlaces de mexicanas con asiáticos". ${ }^{9}$ Este hecho coincidió, dos años más tarde, con un proyecto de ley de relaciones familiares que tendía a restringir la "celebración de matrimonios entre individuos de la raza Asiática con nacionales, y si fuere posible a evitarles por completo, pues está la conciencia pública que esto es una necesidad, porque tales uniones conducen a la degeneración, empobrecimiento y degradación de la raza". ${ }^{10}$ Estas afirmaciones no eran extrañas a otros estados de la República puesto que el gobierno de
Sonora, encabezado por Francisco Elías, ya en octubre de 1930 dictó instrucciones mediante una circular a las autoridades del Registro Civil para que no se autorizara "ninguna unión civil entre mujeres mexicanas y ciudadanos chinos, invocando la Ley número 31 que al Gobernador Bay no le había sido posible implantar pero que había quedado vigente" (Espinoza, 1932: 54).

Tal efervescencia por controlar la presencia china y restringir especialmente los matrimonios con mexicanas se hizo visible en 1929 en Chiapas, cuando el delegado de Salubridad Federal extendió un amplio informe al jefe de la Sección de Beneficencia y Salubridad del Gobierno de Chiapas. Tras visitar diversos municipios chiapanecos con presencia de inmigrantes asiáticos, afirmó que existía "un problema de carácter radical que exige rápida, radical y adecuada solución y debe ser de carácter Federal coordinando la acción de las Secretarías de Gobernación, Relaciones Exteriores, Departamento de Salubridad Pública y Autoridades Civiles del Estado de Chiapas". El problema, por supuesto, no era otro que el aumento de la presencia de chinos, lo que implicaba, además, un crecimiento en el monopolio económico de ciertos giros, como el del comercio. Junto a una aproximación censal al número de migrantes chinos en cada municipio, el informe enumeraba los inconvenientes de tal presencia asiática en Chiapas. La retahíla de enfermedades que poseían y las condiciones antihigiénicas en las que vivían se unían a la descripción de enfermedades consideradas de carácter social, como las toxicomanías, el juego prohibido o la "existencia de Sociedades Secretas que acuden frecuentemente al asesinato".

Otro de los graves problemas señalados en el informe era la relación con mujeres mexicanas, "casi la mayoría de las veces [...] en amasiato". Resultado de estas circunstancias sería el incremento de "hijos naturales". Por lo tanto, los enlaces matrimoniales eran reprobados por los "postulados de la Eugenesia", más que ser "un progreso étnico es una evolución regresiva". Ante tal situación, el autor del texto proponía, entre otras medidas que debían llevar a la expulsión de los asiáticos, modificar las leyes migratorias, prohibir "los enlaces de mexicanas con asiáticos por los notorios perjuicios que originan (evolución regresiva)" y aplicar 
“deportaciones en masa en forma semejante como lo hacen las autoridades Norte Americanas con los Mexicanos".

Un seguimiento de los procesos legislativos y los cambios en la normatividad chiapaneca, en buena medida diseñados en concordancia con lo que ocurría a nivel federal, sería de gran ayuda para discernir cómo se transformó la visión de los inmigrantes y, también, el papel jugado por la mujer en la sociedad.

\section{El certificado prenupcial: una supuesta solución}

Lógicamente, la prohibición del matrimonio entre asiáticos y mexicanas no podía sustentarse en un decir o sentir expuesto por los políticos y funcionarios en turno, sino que tenía que estar correlacionada con una legislación adecuada. De la misma forma, tal legislación estaría en sintonía con las características de la sociedad del periodo y ésta tomó referencias de lo que se consideraba científico en tal momento. La influencia de la eugenesia articulada por Francis Galton fue notoria en México desde principios del siglo XX hasta pasada la Segunda Guerra Mundial. Con respecto al certificado médico prenupcial, en el Congreso Internacional de Medicina celebrado en 1906 se presentaron muchas ponencias relativas a dicho certificado (Mac-Lean y Estenos, 1951: 362). Este aspecto ya se reflejó en la Ley sobre Relaciones Familiares de 1917, que hacía hincapié en este tema y establecía la necesidad de una constancia médica en la que se certificara que no existían enfermedades por parte de alguno de los cónyuges que condicionaran el futuro desarrollo de los hijos de ambos, es decir, de las siguientes generaciones de mexicanos, algo en lo que los eugenistas nacionales insistieron constantemente, como ocurrió en el artículo 131 del Código Sanitario de 1926, en el que se precisaban las patologías que impedían la firma de un contrato matrimonial (Saade, 2004: 26). En definitiva, y como señala Saade:

Nuestros eugenistas, comprometidos también con el lenguaje de "lo social", intentaron con notable eclecticismo determinar quiénes debían ser "los padres de la nueva nación”. Justamente, porque para los abanderados de una teoría de la herencia biológica, la nación aparecía como el producto genealógico del biotipo de sus antepasados (Saade, 2004: 27)

De esta suerte, la idea de "regeneración biológica" se podría ejercer a través de los controles médicos establecidos en la legislación. Esta realidad, por supuesto, no era propia del México posrevolucionario, como recuerda Alexandra Stern (2000: 69) al mencionar la formación intelectual de Gilberto Loyo, quien estudió con el fascista Corrado Gini en la Italia de la década de los treinta. Fue entonces cuando Loyo publicó La política demográfica en México, obra que para Stern se lee "como una lista de deseos de los eugenistas, pues apoya las campañas contra la mortalidad infantil y a favor de medidas de salud pública, los certificados prematrimoniales, la inmigración selectiva de extranjeros 'asimilables', la repatriación de los nacionales mexicanos en Estados Unidos y el fortalecimiento del mestizo mediante programas diseñados para modernizar al indio" (Stern, 2000: 69).

Esa influencia de la llamada ciencia eugénica o eugenesia se constata en las ideas que circulaban alrededor del papel de ciertos inmigrantes en suelo mexicano, pero también se vio reflejada en la legislación: "Respecto de la salud matrimonial en la formalización de la Ley de Certificado Prenupcial de 1935, Decreto número 1709; en el reglamento de la campaña antivenérea de abril de 1940; en la derogación de la reglamentación de la prostitución y en múltiples programas de educación sexual [...]" (Suárez y Ruiz, 2001: 86).

\section{Para concluir}

Múltiples son los aspectos que se convirtieron en bandera del proceso de transformación social tras el triunfo de la Revolución mexicana, como la preocupación racial, con la emergencia del mestizo como proyecto de ciudadano mexicano, la regeneración social como abandono de los anclajes morales y culturales del pasado, o el uso de la ciencia como soporte de dichas transformaciones, tal cual se observa en la 
relevancia otorgada a la actividad física, la higiene, la demografía o la eugenesia. Y todos estos elementos incidieron en el papel jugado por la mujer en la sociedad del momento (Urías, 2004: 95-96), en especial porque sobre ellas recaía la idea de la reproducción con fines de mejoramiento racial (Suárez y Ruiz, 2001: 81), por lo que, tal como señalaba Alfredo M. Saavedra, mediante el concepto de asimilabilidad señalado en su libro de 1934 La eugenesia y la medicina social, había "razas próximas" o "cercanas" que producían mezclas robustas, mientras que el cruce de "razas distantes" daba lugar a progenie indeseable (Stern, 2000: 66).

De ahí que el rol de la mujer, convertida en instrumento de política pública nacionalista, fuera fundamental como reproductora y eje de la pretendida regeneración de la sociedad a través del carácter de portadora de la semilla de los futuros ciudadanos mexicanos. Lo anterior hacía imposible, o al menos no deseable, el contacto con elementos que perturbaran o degeneraran el producto final, y el caso de los chinos es un nítido ejemplo. De ahí que los enlaces matrimoniales con inmigrantes asiáticos se convirtieran en una situación problemática para el país, y propuestas como las plasmadas en la legislación, o hechos como los vividos por las mujeres expulsadas con sus maridos al país de origen de sus consortes, muestran esas políticas dirigidas a la construcción de un nuevo mexicano ajeno, o alejado, de cualquier mezcla racial considerada perjudicial. Explorar esta parte de la historia mexicana en Chiapas seguramente dará luz sobre muchos de los procesos históricos de carácter nacional vividos en los estados de la República, así como del papel de las mujeres en este periodo de conformación del discurso sobre la nación y los propios ciudadanos mexicanos.

\section{Notas}

${ }^{1}$ AHE-CUID, Hemeroteca, La Vanguardia, n. 79, Tuxtla Gutiérrez, 31 de agosto de 1930, pp. 1/4.

2 ASRE, exp. III-121-39, 1933, el Jefe del Departamento Consular, Anselmo Mena, al Jefe del Departamento Diplomático, México, 20 de julio de 1933.
${ }^{3}$ AGN, Fondo Lázaro Cárdenas, caja 925, exp. 549.5/40, Amable Palacios viuda de Chong al Presidente de la República, Tapachula, 17 de enero de 1940.

${ }^{4}$ AHE-CUID, Secretaría de Gobierno, tomo XIII, exp. 116. Correspondencia con el Presidente de la República, 1925, el Presidente del Comité Anti-Chino de Torreón al Gobernador de Chiapas, Torreón, 25 de agosto de 1925.

${ }^{5}$ AHE-CUID, Secretaría de Gobierno, tomo XIII, exp. 116, Correspondencia con el Presidente de la República, 1925, el Oficial Mayor por el Secretario General de Gobierno de Chiapas al Presidente del Comité AntiChino de Torreón, Tuxtla Gutiérrez, 10 de septiembre de 1925.

${ }^{6}$ AGN, Dirección de Gobierno, caja 10, exp. 28, 2.360 (29) 8103, Acta Constitutiva y Estatutos de la "Unión Nacionalista Mexicana” (Pro-Raza y Salud Pública), México D.F., 1930.

${ }^{7}$ AGN, Dirección General de Gobierno, caja 10, exp. 28, 2.360 (29) 8103, José A. Espinoza, Presidente del Comité Pro-Raza del D.F. al Secretario de Gobernación, México 29 de septiembre de 1933.

${ }^{8}$ DDHCD, Legislatura XXIX, año legislativo I, periodo ordinario, 21 de septiembre de 1920, pp. 8-10.

${ }^{9}$ AGN, Fondo Emilio Portes Gil, Documentación de la Administración Pública, caja 44, exp. 2/549/104, el Gobernador de Chiapas al Presidente de la República, Tuxtla Gutiérrez, 31 de octubre de 1929.

10 AHE-CUID, Hemeroteca, "Proyecto de Ley de Relaciones Familiares", en La Vanguardia, n. 128, Tuxtla Gutiérrez, 20 de agosto de 1931, p. 3.

${ }^{11}$ AGN, Fondo Emilio Portes Gil, Documentación de la Administración Pública, caja 44, exp. 2/549/104, el Jefe de la Sección de Beneficencia y Salubridad del Gobierno de Chiapas al Presidente de la Comisión Permanente del H. Congreso de Chiapas, Tuxtla Gutiérrez, 13 de mayo de 1929.

\section{Referencias bibliográficas}

Comunidades Eclesiales de Chablekal y Dzibilchaltún (comp.) (1991), Nuestros abuelos nos contaron. Mérida: Programa de Apoyo a la Cultura Municipal y Comunitaria de la Dirección General de Culturas Populares. 
Espinoza, José Ángel (1931), El problema chino en México. México: Porrúa.

Espinoza, José Ángel (1932), El ejemplo de Sonora. México: s.e. González Navarro, Moisés (1994), Los extranjeros en México y los mexicanos en el extranjero, 1821-1870, vol. III. México: COLMEX.

Jiménez Domínguez, Olga Tatiana (2010), Discursos periodísticosy legalesen torno a la violencia doméstica: apuntes para el estudio de la dinámica familiar en época de cambios en Chiapas, 1930-1940, Tesis de maestría en Ciencias Sociales y Humanísticas, UNICACH, San Cristóbal de Las Casas, Chiapas, México.

Lisbona Guillén, Miguel (2014), Allí donde lleguen las olas del mar... Pasado y presente de los chinos en Chiapas México: PROIMMSE-IIA-UNAM/CONACULTA/Gobierno del Estado de Chiapas.

Mac-Lean y Estenos, Robert (1951), "La eugenesia en América". En Revista Mexicana de Sociología, vol. 13, núm. 3, septiembre-diciembre, pp. 359-387.

Pardinas, Felipe (1982), Relaciones diplomáticas entre México yChina, 1898-1948, 2 t. México: Secretaría de Relaciones Exteriores.

Saade Granados, Marta (2004), “iQuiénes deben procrear? Los médicos eugenistas bajo el signo social (México, 1931-1940)". En Cuicuilco, vol. 1l, núm. 31, mayo-agosto, pp. 1-36.

Stern, Alexandra (2000), "Mestizofilia, biotipología y eugenesia en el México posrevolucionario: hacia una historia de la ciencia y el estado, 1920-1960". En Relaciones. Estudios de Historia y Sociedad, vol. XXI, núm. 81, pp. 58-91.
Suárez y López-Guazo, Laura y Rosaura Ruiz Gutiérrez (2001), "Eugenesia y medicina social en el México posrevolucionario". En Ciencias, núm. 60-61, octubre, pp. 80-86.

Urías Horcasitas, Beatriz (2004), "De moral y regeneración: el programa de 'ingeniería social' posrevolucionario visto a través de las revistas masónicas mexicanas, 1930-1945”. En Cuicuilco, vol. 11, núm. 32, septiembrediciembre, pp. 87-119.

\section{Abreviaturas}

AGN: Archivo General de la Nación, México D.F. AHE-CUID: Archivo Histórico del Estado-Centro Universitario de Información y Documentación (Universidad de Ciencias y Artes de Chiapas), Tuxtla Gutiérrez.

ASRE: Archivo de la Secretaría de Relaciones Exteriores, México D.F.

DDHCD:Diario de Debates del Honorable Cámara de Diputados (versión digital).

\section{Ficha de los documentos}

AHE-CUID, Hemeroteca, Editorial, "Proyecto de Ley de Relaciones Familiares", en La Vanguardia, n. 128, Tuxtla Gutiérrez, 20 de agosto de 1931, p. 3.

AHE-CUID, Hemeroteca, Sección "Recibimos y Publicamos", en Evolución, núm. 9, Tuxtla Gutiérrez, 8 de junio de 1922, p. 2. 
Imagen 1. Propuestas legislativas contra el matrimonio con chinas

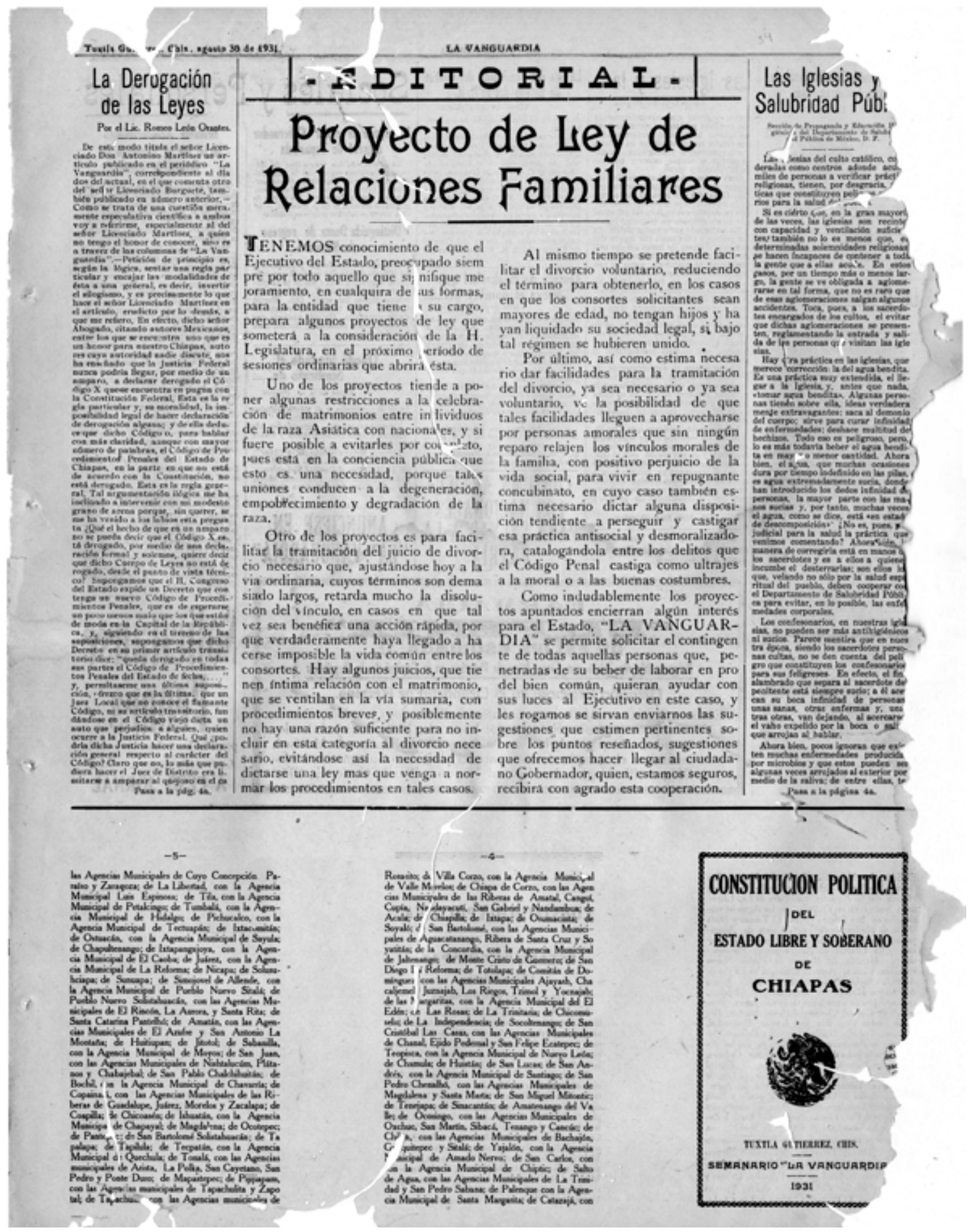


Imagen 2. Reacción antichina de la sociedad civil

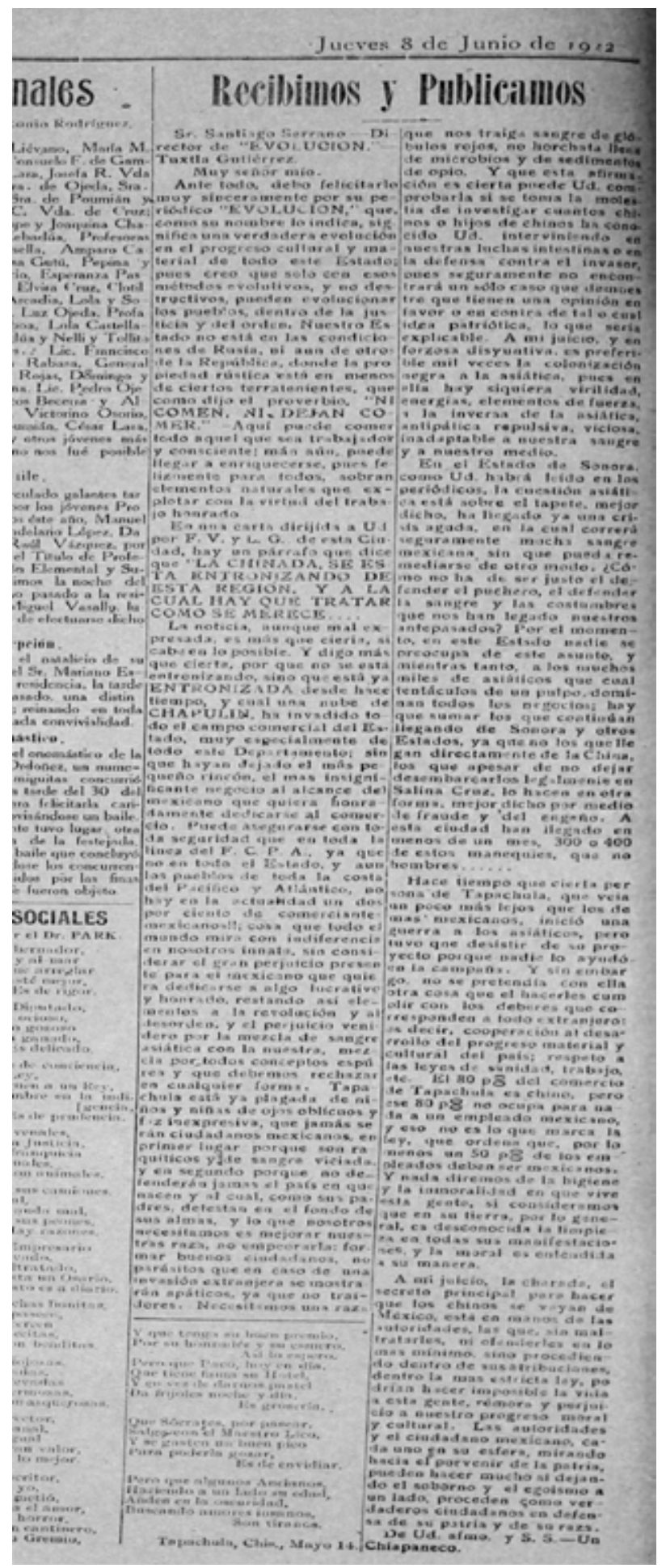

